

\title{
Forensic Analytical Chemistry
}

\author{
Bruno Spinosa De Martinis \\ Associate Professor (Forensic Chemistry) \\ University of São Paulo \\ Faculdade de Filosofia, Ciências e Letras de Ribeirão Preto \\ Department of Chemistry \\ Laboratory of Forensic Toxicological Analysis \\ martinis@usp.br
}

The word "forensic" comes from the Latin language and it means public, to the forum or public discussion; argumentative, rhetorical, belonging to debate or discussion. A relevant, modern definition of forensic is relating to, used in, or suitable to a court of law. Any science used for the purposes of the law is a forensic science [1].

The forensic sciences are requested around the world to resolve civil disputes, to justly enforce criminal laws and government regulations, and to protect public health. Early on, forensic sciences became identified with law enforcement and the prosecution of criminal cases - an image reinforced by books, television, and movies. However, this is misleading because forensic sciences are objective, unbiased, and apply equally to criminal, civil, or other legal matters [1].

Forensic sciences encompass different disciplines, such as medicine, law, engineering, dentistry, biology, physics, and chemistry, among several others. In fact, Forensic Science is recognized itself as a multidisciplinary science. Forensic chemistry can be defined as the application of chemical expertise to assist in the resolution of legal cases. More specifically, forensic analytical chemistry is one of the most useful and instigating areas of investigation, and it has wide application in the analysis of licit and illicit drugs in different matrices; the analysis of adulteration of foodstuffs, such as olive oil and distilled beverages; fuels and vehicle chassis adulteration; and frauds in works of art and arson analysis.

Forensic analytical chemistry and its powerful methods of analysis, such as gas chromatography (GC), mass spectrometry (MS), high performance liquid chromatography (HPLC), thin layer chromatography (TLC), immunoassays, atomic absorption/atomic emission (AA/AE), inductively coupled plasma emission (ICP/AES) and mass spectrometry (ICP/MS), scanning electron microscopy (SEM), Fourier transform infrared spectrometry (FTIR), ultraviolet/visible spectrometry (UV/Vis), and electrophoresis, are now indispensable tools in the context of forensic expert activity as an auxiliary element of justice. Among these applications, there is demand for the investigation of licit and/or illicit drugs in biological specimens, both in vivo and postmortem, especially considering the continuous emergence of new synthetic drugs and large drug abuse, which is responsible for serious public health problems throughout the world, greatly impacting youths.

Although the study of the science that studies toxic substances and their effects began in the early 1800s, the knowledge of poisons and poisonings had existed for thousands of years. Poisonings by opium, arsenic, and hydrocyanic acid had been reported in Europe during the Middle Ages. It was during that time that Philippus Aureolus Theophrastus Bombastus von Hohenhein, also known as Paracelsus, observed that any substance could be a poison, depending on the dose. In 1814, Mathieu Joseph Bonaventure Orfila, the head of the Department of Legal Medicine at the University of Sorbonne (France), made the first systematized and categorized study of some poisons and isolated arsenic from various postmortem biological samples. He was the pioneer in stating that a poison needs to be absorbed or enter the bloodstream to manifest its toxic effects [2]. 
In 1851, Jean Servais Stas developed the first effective analytical method for extracting alkaloids from biological samples. The procedure for the extraction was largely modified years later by Friedrich Julius Otto, who was able to isolate pure alkaloids. This analytical method became known as the StasOtto Method and it is still fundamental for drug extraction [2].

Licit and illicit drugs, including ethanol, cocaine, marijuana, amphetamines, benzodiazepines, and barbiturates, have long been the most studied analytes, especially in biological samples from living and dead individuals, such as blood, urine, viscera, and hair. More recently, new psychoactive substances, better known as NPSs, such as synthetic cannabinoids, substances derived from Fentanyl and Cathinones, have come into the spotlight of forensic analytical chemistry. In this scenario, it is crucial the research, development, and validation of new analytical techniques to attend the large demand from the modern society for the elucidation of forensic cases.

\section{REFERENCES}

1. https://www.aafs.org/ (accessed on February $25^{\text {th }}, 2019$ ).

2. Levine B. Postmortem Forensic Toxicology. In: Levine B. Principles of Forensic Toxicology, American Association for Clinical Chemistry, 1999, pp 1-12. 